\title{
Students' Social Involvement in the Community: Satisfaction, Motivations and Long-Term Influences
}

\author{
Dr. Ety Elisha \\ Department of Criminology, \\ The Max Stern Yezreel Valley College. \\ Dr. Sarit Alkalay \\ Department of Psychology, \\ The Max Stern Yezreel Valley College. \\ Prof. Javier Simonovich \\ Dean of Students and lecturer in the Department of Human Services, \\ The Max Stern Yezreel Valley College.
}

\begin{abstract}
The objective of the current research was to examine the satisfaction derived from, motivations for and long-term effects of social activity in the community carried out by students under academic sponsorship. Fifty-eight undergraduate students participated, during their studies, in a course of social involvement in the community, aimed to benefit disadvantaged populations (children and youth at risk, and people with special needs). Participants completed two questionnaires: one examined motivation for engaging in social activity in the community, and the other examined the long-term influences of this activity. The findings show that most of the participants derived high satisfaction from their social activity. No significant correlations were found between satisfaction and motivation for social activity (egoistic/altruistic/materialistic). The long-term influences of community social activity were expressed primarily in terms of achieving personal gains. Correlations between different types of motivations and longterm effects of the social activity showed that each of the examined motivations exerted a positive effect, with slight advantage to altruistic motive. Additionally, women expressed higher satisfaction from their social activity, compared to men. Findings can serve as a basis for initial assessment of community social activity as carried out in an academic setting, and reinforce academic institutions in supporting such noteworthy activities.
\end{abstract}

Keywords: Social involvement; community activity; students; academia; satisfaction; motivations; long-term influences.

\section{INTRODUCTION}

Research examining the effects of social activity in the community carried out by students as part of academic courses, points to the many advantages of such activity as well as to the high degree of satisfaction experienced by students involved in these courses. The current study attempts to expand the knowledge on this topic.

\section{Students' social activity in the community under academic sponsorship}

In recent years, institutions of higher education in various Western countries have begun to place renewed emphasis on developing the civic-social identity of their students and to encourage them to volunteer in their communities as part of their academic courses. Because academic studies constitute a decisive period in students' development, social activity in the 
community plays a major role in shaping and developing their identity (Seider, 2007). The objective of these courses is to develop civic consciousness among the students, to raise their awareness of social problems, and to intervene for the benefit of others. Currently, such courses are included in the undergraduate curriculum of colleges and universities in the U.S. exposing students to a variety of social topics, such as education, health, poverty and social inequality. The underlying assumption of these courses is that knowledge acquired through formal education should not be used exclusively for personal benefit but rather for the benefit of the public at large (Hatcher \& Studer, 2015).

In the U.S., social activity courses, such as service learning, are offered to the students, leading to an increase in volunteer rates among undergraduate students, which currently stands at 27\% (Burns, 2011; Hatcher \& Studer, 2015). Similarly, higher education institutions in England have recognized the potential of community activity for students, for the recipients and for the community as a whole. Such activity can help develop students' academic skills and their employment abilities as well as to improve connections between academic institutions and local community. This step expresses the current trend in Western nations, including Israel, according to which academia leads, supports and funds community social activity while granting students accreditation and integrating such courses into the formal curriculum (Brewis \& Holdsworth, 2011).

\section{Motivations for social voluntary activity in the community}

Research studies exploring the motivations for volunteerism, found that personal interests (egoistic) and social interests (altruistic) are equally involved (Clary, Snyder, \& Stukas, 1998; Hustinx, Cnaan, \& Handy, 2010).

Clary et al. (1998) identified six main reasons for social voluntary activity deriving from egoistic and altruistic motives: 1 . values and concern for others; 2 . understanding and learning about the topic; 3. interaction and social recognition; 4. desire for self-development and selfenrichment; 5. gaining professional experience for a future career; and 6. developing new skills.

\section{Satisfaction and long-term influences of community social activity}

Research reports a high level of satisfaction among students who were involved in community social activity under academic sponsorship. This satisfaction stems mainly from students' feelings that they are doing something worthwhile for others (Astin et al., 1999; Steinberg at al., 2011), and the academic support they received from the course facilitators (Brewis \& Holdsworth, 2011).

Other studies point to the long-term influence of students' social activity in the community, including increased self-esteem, acquiring values (Ethridge, 2006; Mobley, 2007; Prentice, 2007); developing social and civic awareness, more in-depth understanding of social problems, higher problem-solving ability and greater willingness to volunteer in the future (Astin, Sax, \& Avalos, 1999; Mobley, 2007; Steinberg, Hatcher, \& Bringle, 2011).

Astin and Sax (1998) found that students at 42 academic institutions in the US, that participated in service learning courses, reported that their social activity in the community had a positive impact on their lives in a variety of areas (e.g., developing academic and life skills, problem-solving abilities, community commitment). The study also found that community activity helped the students to formulate their identity, and develop better understanding of people from different backgrounds (Astin \& Sax, 1998). These studies 
indicate that social activity leads to developing a sense of competence, efficacy and empowerment at the individual and community levels (Sadan, 1997; Mueller, 2005).

A recent study conducted in Israel (Golan \& Goldner, 2016) indicates the positive long-term influences of social activity in the community under academic sponsorship. The research included 816 participants examined five to ten years after completing their BA degrees. Participants, mostly women, carried out their social activity under the auspices of units for social involvement at several academic institutions. Most of them participated in "Perach" tutorial project ${ }^{1}$, while others volunteered in sexual assault aid centers. Findings show that 82\% perceived their social activity as positive, expressed in increased self-confidence, development of a sense of self-efficacy and leadership skills, acquisition of interpersonal tools (e.g., teamwork ability and lesson plan construction), and development of social-political awareness. Additionally, those who perceived their social activity as positive tended to become active citizens as adults (Golan \& Goldner, 2016).

\section{Social involvement activity under academic sponsorship in Israel}

In recent years, social involvement in the community constitutes one of the major topics on the agenda of the Council for Higher Education (CHE) in Israel. Hence, academic institutions promote active involvement in the community, via academic courses based on students' social activity (CHE, Planning and Budgeting Committee - PBC, 2013). Beginning in 2010, the CHE of Israel has spearheaded an innovative participatory model that supports and funds projects of social involvement in the community through academic courses. This model is based on the assumption that experiencing in the field with the exposure to knowledge in areas of activity will provide students new skills, benefiting them in their future. The objective of this model is to support and promote disadvantaged populations (CHE, PBC, 2013).

\section{SUMMARY AND HYPOTHESIS}

Most studies on social involvement in the community examined various aspects of this activity, and found that these courses had greater long term positive effects on the students compared to those who engaged in such activity not within an academic course, such as increased selfesteem, development of social awareness, and a sense of empowerment, career development and high satisfaction (Astin et al., 1999; Brewis \& Holdsworth, 2011; Mobley, 2007; Steinberg et al., 2011).

Over the past five years, the Max Stern Yzreel Valley College in Israel has been offering courses of social involvement in the community, launched by the office of the Dean of Students ${ }^{2}$ and funded by the PBC of the CHE in Israel. The facilitators of these courses have noticed significant changes in student's perspectives, as it emerged from feedback and personal reflections they submitted at the end of the academic year. However, no study has systematically examined these changes and influences prior of this study.

The objective of the current study is to examine the satisfaction, motivations and long-term effects of social activity in the community among students who participated in courses of social community involvement during their undergraduate studies.

\footnotetext{
1 Perach - a project operated in academic intuitions in Israel, based on activities carried out by students in the community with needy population, in return for a scholarship.

2 Note: At the time of the study, the Dean of Students was one of the authors of this article,
} 


\section{Research Hypotheses}

1. A correlation will emerge between satisfaction with community social activity and the motivation for carrying out that activity (egoistic / altruistic / materialistic).

2. A positive correlation will emerge between current occupation in social sciences field and satisfaction with the community social activity. Participants employed in the field of their past social activity will report higher satisfaction.

3. Differences will emerge between the types of long-term effects of community social activity that are going to be manifested more in the achievement of personal benefits than in the development of social awareness.

4. A positive correlation will emerge between altruistic motivation to community social activity and the general long-term effects of this activity.

5. A positive correlation will emerge between egoistic motivation to carry out community social activity and the general long-term effects of this activity.

6. A positive correlation will emerge between materialistic motivation to carry out community social activity and the general long-term effects of this activity.

\section{Research Participants}

\section{METHOD}

Participants were 58 B.A. graduates at the Max Stern Yzreel Valley College. During their undergraduate studies they participated in courses on social involvement in the community offered in the-Criminology and Behavioral Sciences departments. ${ }^{3}$. On average, 13 students per year were enrolled in each such course. The relatively small number of students who took these courses over the past five years $(\mathrm{N}=104)$, made it difficult to recruit more participants in the study.

The social activity of the research participants took place in various community settings that aim to promote disadvantaged and at-risk population groups such as children and teens (e.g., boarding schools, community center), and people with disabilities (e.g., mental health facilities, rehabilitation hospitals).

As for the socio-demographic characteristics of participants, 81\% were women and 19\% men. Their average age was 33.09 years ( $S D=12.93)$. Most were born in Israel $(87 \%)$, while $10 \%$ stated they were born in the former Soviet Union and 1.7\% indicated another place of birth. Most were Jewish (86.2\%), while 12.1\% were Muslim Arabs and 1.7\% were Christian Arabs. Fifty percent were married, $41.4 \%$ were single and $1.7 \%$ widowed.

Participants were asked to indicate their current occupational field. Their answers were classified into three categories: a) community and social services occupations (e.g., working with disadvantaged population, special education, Non-Profit Organizations (NPOs)/NonGovernment Organizations (NGOs); b) occupations not related to social services (e.g., service, security, consultation or management in for-profit organizations); c) unemployed. The majority of the participants $(43.1 \%)$ indicated they were employed in non-social services occupations, while $24.1 \%$ in social services field and $32.8 \%$ stated they were unemployed.

The majority of the participants, (51.7\%) indicated they had volunteered previously to taking the community social involvement course.

${ }^{3}$ Note: These courses were delivered under the guidance of two of the article's authors, 


\section{Research Tools}

Three questionnaires were used in the current study:

1. Personal details and satisfaction with community social activity. This questionnaire includes socio-demographic data such as gender, age, marital status, country of birth, religion, economic status, employment status, and a question regarding the place of their social activity. We also added a question that examined the extent of participants' satisfaction with their social activity.

2. Questionnaire examining motivations for volunteering in the community: $A$ questionnaire complied by Cnaan \& Goldberg-Glen (1991), with high reliability ( $=0.86$ ). The questionnaire consisting of 21 items referring to egoistic, altruistic and materialistic motivations, on a scale ranging from one (do not agree) to five (absolutely agree). Scores ranged from 2-5 $(\mathrm{M}=3.17, \mathrm{SD}=0.60)$. The internal consistency of the entire questionnaire was 0.87 Cronbach's alpha.

The questionnaire included three indexes reflecting the three motivations that were examined: egoistic (self-directed), altruistic (other directed) and materialistic (utilitarian), as follows:

Index of egoistic motivations - includes six statements that examined the degree to which respondents agreed with self-directed personal motives in choosing to carry out volunteer activity (questions 1, 6, 8, 10, 14, 18). For example: "Expand my horizons"; "Gain practical experience"; "It's challenging." Scores ranged from 2-5 $(\mathrm{M}=3.33, \mathrm{SD}=0.76)$. The internal consistency of this index was 0.686 Cronbach's alpha.

Index of altruistic motivations - includes nine statements that examined the degree to which respondents agreed with motives related to social, moral and ethical concerns in choosing to carry out volunteer activity (questions 2, 3, 7, 11, 13, 15, 17, 20, 21). For example: "Identify with the goals of the project"; "God expects people to help one another"; "Volunteering is a way to fix social injustice." Scores ranged from 2-5 (M=3.24, SD = 0.67). The internal consistency of this index was 0.772 Cronbach's alpha.

Index of materialistic motivations - includes six statements that examined the degree to which respondents agreed with utilitarian motives (expectation to receive material and non-material rewards) in choosing to carry out volunteer activity (questions 4, 5, 9, 12, 16, 19). For example: "I was lonely"; "I had nothing better to do with my free time"; " It is a way to develop social ties." Scores ranged from $1-5(\mathrm{M}=2.93, \mathrm{SD}=0.64)$. The internal consistency of this index was 0.663 Cronbach's alpha.

We also added four open-ended questions to this questionnaire in order to obtain extensive answers to the motives for participating in community involvement course: 1) Describe in your own words why you chose to take a social involvement course. 2) What were your expectations from this course? 3) Did you meet your expectations? 4) How satisfied are you from your social involvement activity?

3. Questionnaire examining long-term influences of social activity. The researchers constructed this questionnaire in order to examine various aspects related to the long-term effects on the participants of their social activity. We calculated long-term influences score by summing the fifteen statements that the participants responded to, on a scale ranging from 1 (not at all) to 5 (to a very great extent). Scores ranged from 17-75 (M = 49.79, SD = 6.13). Internal consistency of the entire questionnaire was 0.94 Cronbach's alpha.

The questionnaire included two indexes: social awareness and personal contribution. Social awareness index - includes six statements that examined the degree to which respondents agreed regarding the impact of their social activity on raising their social consciousness (e.g., changes in perceptions regarding disadvantaged populations, developing empathy for others). Scores ranged from 6-30 $(\mathrm{M}=21.28$, SD = 6.13). The internal consistency of this index was 0.909 Cronbach's alpha. 
Personal contribution index - includes nine statements that examined the degree to which respondents agreed regarding the personal contribution made by their social activity (e.g., increasing sense of self-esteem, finding employment in the field of activity). Scores ranged from 9-35 $(\mathrm{M}=23.5, \mathrm{SD}=6.73)$. The internal consistency of this index was 0.905 Cronbach's alpha.

\section{Research procedure}

The Ethics Committee of the Max Stern Yzreel Valley College approved this research (Approval No. - 2016-37). We gathered information regarding undergraduate students who participated in community social involvement courses as part of their BA studies during the last four academic years (2013-2017). The questionnaires were distributed by email.

\section{FINDINGS}

First, we will present the findings emerging from analysis of the questionnaires completed by the participants with respect to the main research hypotheses. Then, we will present the participants' responses to the open questions added to the first questionnaire (motivations for volunteer work).

\section{Satisfaction from community social activity as part of a course on social involvement}

One of the questions on the personal data questionnaire related to the degree to which participants were satisfied with their community social activity as part of the social involvement course. The results show that $36.6 \%$ of the respondents reported that they were "extremely satisfied," 37\% stated they were "very satisfied," 26.4\% reported they were "somewhat satisfied" and only 5.7\% reported they were "not at all satisfied." That is, a decided majority of the research participants $(39.6 \%+37 \%=76.6 \%)$ indicated a high level of satisfaction from their social activity.

\section{H1: Correlation between satisfaction with community social activity and motivation}

Examination of the hypothesis that a correlation would emerge between satisfaction with community social activity and motivation for such activity (egoistic / altruistic / materialistic) included calculating three Spearman's rank correlation coefficients. No significant correlations emerged between the variables, as follows:

H1a: No significant correlation emerged between egoistic motives for community social activity and satisfaction with such activity $(r=0.178, \mathrm{p}=0.221)$.

H1b: No significant correlation emerged between altruistic motives for community social activity and satisfaction with such activity ( $r=0.037, \mathrm{p}=0.802)$.

H1c: No significant correlation emerged between materialistic motives for community social activity and satisfaction with such activity $(r=0.128, p=0.376)$. Hence, the hypothesis was rejected.

Nevertheless, examination of the cross-tabulation tables for each type of motive relative to satisfaction with community social activity yielded the following findings:

Materialistic motive: Among all the respondents who reported agreeing largely with respect to this measure $(n=4), 75 \%$ indicated they were extremely satisfied with their community social activity, while the remainder (25\%) reported being somewhat satisfied.

Egoistic motive: Among all the respondents who reported agreeing largely with respect to this measure $(n=7), 71.4 \%$ indicated they were extremely satisfied with their community social activity, while the remainder $(28.6 \%)$ reported being very satisfied or somewhat satisfied. 
Altruistic motive: Among all the respondents who reported agreeing largely with respect to this measure $(n=9), 55.6 \%$ indicated they were extremely satisfied with their community social activity, while the remainder (44.6\%) reported being somewhat satisfied.

\section{H2: Correlation between current employment in social science field and satisfaction with the community social activity.}

No significant Chi square correlation was found between current employment in the field of social activity and satisfaction with the community social activity the participants conducted as part of their social involvement course. $\left(\chi^{2}{ }_{(4)}=2.508, p>0.05\right)$. Hence, the hypothesis was rejected.

\section{H3: Differences in the long-term effects of community social activity}

The third hypothesis claims that long-term effects would be manifested more in the achievement of personal gains (personal contribution index) than in the development of social awareness (social awareness index). T-test for dependent samples was conducted to verify this hypothesis. The results indicated a significant difference between the averages with a small effect $\left(t_{(51)}=4.04, p<0.05 . \mathrm{d}=0.16\right)$. The average on the personal contribution index $[M=23.5$, $S D=6.73]$ was higher than the average on the social awareness index $[M=21.28, S D=6.13]$. In addition, the Pearson correlation coefficient test revealed a strong and positive significant correlation $\{0.000\}$ between the two variables $(r=0.816, p<0.05)$. In other words, for each participant there was a correlation between development of personal contribution and development of social awareness. Nonetheless, the long-term effects were more evident in obtaining personal benefits than in developing social awareness. Hence, the hypothesis was validated.

\section{H4: Correlation between the altruistic motivation and the general long-term effects of community social activity}

A positive but weak significant Spearman's rank correlation emerged between the altruistic motivation for community social activity and the general long-term effects of this activity ( $\mathrm{r}=$ $0.379, \mathrm{p}=0.006)$.

\section{H5: Correlation between the egoistic motivation and the general long-term effects of community social activity}

A positive but moderate significant Spearman's rank correlation emerged between the egoistic motivation for community social activity and the general long-term effects of this activity $(\mathrm{r}=$ $0.521, \mathrm{p}=0.000)$.

\section{H6: Correlation between the materialistic motivation and the general long-term effects of community social activity}

A positive but moderate-high significant Spearman's rank correlation emerged between the materialistic motivation for community social activity and the general long-term effects of this activity $(\mathrm{r}=0.57, \mathrm{p}=0.000)$.

To predict the factors influencing the effects of community social activity over the long term, we calculated a multiple linear regression model and entered the following independent variables: egoistic motives (self-directed), altruistic motives (social, ethical, moral) and materialistic motives (utilitarian). The resulting regression model was significant $(\mathrm{F}(3,46)=$ $14.629, \mathrm{p}<0.05)$. The model explains $48.8 \%$ of the variance in the general long-term effects of community social activity. Altruistic motives emerged as the strongest predictor $(\beta=0.411$, $\mathrm{p}<0.05)$. 
* Model significance 0.000 , beta significance for altruistic motives 0.016 .

* All exhibit a strong and positive significant correlation with the variable "long-term effect of community social activity".

Egoistic motives $(\mathrm{r}=0.62, \mathrm{p}=0.000)$

Altruistic motives $(\mathrm{r}=0.654, \mathrm{p}=0.000)$

Materialistic motives $(\mathrm{r}=0.562, \mathrm{p}=0.000)$

Correlation between satisfaction from community social activity and respondent gender

We examined additional correlations between the research variables (motives for community social volunteer work, general long-term effects of social activity and satisfaction from such activity) and the socio-demographic variables of the research participants. No significant findings emerged in the context of the socio-demographic variables, with the exception of gender, as described below.

Chi-square analysis was used to examine the correlation between degree of satisfaction with social activity and respondent's gender. A significant correlation $\{0.027\}$ that was positive and moderate $\left(r_{c}=.454\right)$ emerged between the variables $\left(\chi^{2}{ }_{(4)}=10.92, p<0.05\right) .77 .8 \%$ of the female indicated they were very satisfied, compared to only $22.2 \%$ of the male. Similarly, $76.2 \%$ of the female indicated they were extremely satisfied, compared to only $23.8 \%$ of the male.

\section{Participants' responses to the open questions}

The four open questions of the questionnaire examine respondents' motivations for volunteering. Participants responded verbally as a way to provide an in-depth picture of their motives, expectations and satisfaction from their community social activity. Their responses are summarized below.

1. Choice of a course on community social involvement. The majority of participants $(n=52)$ cited altruistic motives while deciding to take the community social involvement course: "desire to contribute to others"; "to help others"; "identify with disadvantaged population groups." At the same time, many also noted egoistic motives: "acquiring knowledge in area of study"; "acquiring experience in the field"; "sounds interesting"; "to try something new and break up the routine." Some respondents $(n=6)$ mentioned technical motives that can be considered materialistic/utilitarian motives: "fits into my schedule"; "there's no exam in this course."

2. Expectations from social activity. Many of the participants $(n=34)$ reported personalegoistic expectations: "to learn and develop in my area of study"; "to expand my knowledge about special population groups"; "to acquire practical tools and experience that will help me find work in this field"; "to connect to the field"; "to understand my direction in life"; "to feel that I'm doing something meaningful"; "to boost my selfconfidence"; "to feel good with myself." Some of the respondents $(\mathrm{n}=20)$ cited altruistic expectations, often at the same time: "to help people who need me"; "to help the community"; "to do good for those in need and to make them happy"; "to make a change"; "to give of myself to others." A few of the participants $(n=4)$ stated that they did not have any special expectations.

The above findings indicate that the motives for choosing to take the course on community social involvement (both altruistic and egoistic) for the most part coincide with the participants' expectations regarding community social activity with disadvantaged population groups (personal-egoistic expectations and altruistic expectations). Nonetheless, the motives placed more emphasis on the altruistic aspects while the expectations stressed the personal-egoistic side more. 
3. Did you meet your expectations? Most of the participants $(n=49)$ gave a positive response to this question, while describing the factors that helped them in fulfilling their expectations: "I developed good relationships with the people I worked with"; "I received great support from the course lecturer"; "My activity got good evaluations from those I worked with"; "Volunteering once a week was a lot of fun and very satisfying"; "I believe that I helped"; "I was exposed to an unfamiliar world, I helped people and I acquired tools to work with special population groups"; "I made new contacts"; "It was a new and challenging experience"; "I will never forget the smiles on the faces of the senior citizens I worked with." A minority of the participants $(n=8)$ gave a negative response to this question and often explained why they didn't meet their expectations: "I did not manage to implement everything I wanted to do"; "There wasn't enough time. Once a week for a few hours makes it difficult to really connect with others." Only one participant did not answer this question.

4. Satisfaction from community social activity. A decisive majority of the participants indicated being quite satisfied and even extremely satisfied with their community social activity $(\mathrm{n}=43)$, citing the following reasons: "I really enjoyed the work and I learned a lot about myself"; "I am very satisfied with the volunteer work, which opened doors for me to the professional world. Today I am the director of the youth club where I worked"; "I enjoyed myself very much. We were warmly received at the youth village and we felt we were doing something meaningful for them"; "It was an unforgettable experience"; "It was great-I helped and made others happy"; "It's a great feeling to give and help others." A minority of the participants $(n=15)$ reported on partial or low satisfaction, mostly without providing details. Their responses referred primarily to difficulties in developing meaningful relationships with their recipients.

\section{DISCUSSION}

In line with the current trend in institutions of higher education in Western countries, primarily in the US and England (Brewis \& Holdsworth, 2011; Burns, 2011; Hatcher \& Studer, 2015; Seider, 2007), the academic institutions in Israel also recognize the importance and benefits of students' social involvement in the community. In recent years, the Israeli CHE started to support and fund students' social activity projects, such as courses of social involvement in the community (Council for Higher Education, Planning and Budgeting Committee, 2013). The purpose of the current study was to examine the satisfaction derived from, motivations for and long-term effects of community social activity among Israeli college graduates who participated in courses on social involvement in the community during their undergraduate studies. The research participants majored in criminology and in behavioral sciences; they performed their social activity in various settings aims to promote disadvantaged population, including at-risk children and teens and people with disabilities.

About half of the research participants (51.7\%) indicated they had volunteered in the past, prior to their participation in community involvement courses. This suggests that the participants' decision to carry out social activity stemmed, from at least a considerable part, of their earlier tendency toward caring, volunteering and acting for the benefit of the needy in society. Another major finding is that most participants (76.6\%) reported high satisfaction from their community social activity as part of the course. One of the explanations provided by the students was the academic support they received on the part of the course facilitators. Another explanation was their feeling that they were doing something meaningful and valuable for others. These findings are in accordance with previous studies (Astin et al., 1999; Brewis \& Holdsworth, 2011; Mobley, 2007; Steinberg et al., 2011). 
The first research hypothesis explored the correlation between satisfaction derived from community social activity and the participants' motivations for carrying out such activity (egoistic / altruistic / materialistic). This hypothesis was not confirmed. The explanation could be the small sample size. It is also possible that gathering the various motivations into a single category without separating them into different motivation categories did not provide an accurate picture, since each one exerts a differential influence. Therefore, a more accurate analysis was conducted in a subsequent stage providing different findings for each separate motive factor. Notably, the content analysis of the open questions concerning motivations for carrying out community social activity, supports this assumption. This analysis indicates that most respondents reported of mixed motives, mainly altruistic and egotistic. This finding is consistent with previous studies, which found mixed motivations for carrying out volunteer activity (Clary, Snyder, \& Stukas, 1998; Hustinx et al., 2010).

In the cross-tabulation tables used to examine participants' satisfaction derived from the social activity relative to each motivation separately, examination of the materialistic and the egotistic motives indicated that most participants who reported a high agreement with this motive also reported a high level of satisfaction (75\% and $71.4 \%$, respectively). In contrast, only $55.6 \%$ of the respondents who reported a high agreement with altruistic motive reported a high level of satisfaction. This interesting finding somewhat contradicts intuitive assumptions regarding this matter. One possible explanation is that individuals, who are motivated by altruistic motives, have higher expectations that are more difficult to meet and to measure in the short term, which may impair their satisfaction.

The second research hypothesis, examined the correlation between current occupation in the field of social sciences and satisfaction with the community social activity conducted as part of an academic course of social involvement in the community. This hypothesis was also not confirmed. The size of the sample may have had an impact here as well. Nonetheless, around a quarter (24\%) of the respondents reported of current occupation in the field of social services.

The third research hypothesis, examined the divergence in the types of long-term effects of community social activity. These effects were examined by two indices: social awareness (e.g., increased social awareness) and personal contribution (e.g., current employment in the field of their social activity). This hypothesis was confirmed. This finding is consistent with previous studies indicating that academic courses of social involvement in the community offers many inherent advantages in a variety of areas of life, such as developing academic skills, increasing self-esteem, acquiring values, developing civic and social consciousness, developing life skills and developing a career (Golan and Goldner, 2016; Astin \& Sax, 1998; Astin et al., 1999; Ethridge, 2006; Mobley, 2007; Prentice, 2007).

The influences of community social activity found in our study contributed to empowerment on both, the individual and the social-community levels, expressed in development of a sense of ability, and self-efficacy (Astin \& Sax, 1998; Mueller, 2005). This is reflected in the participants' responses to the open question regarding their expectations of social activity. Participants reported on altruistic and egoistic expectations, such as the desire to learn, develop and become familiar with the field of study; to understand their direction in life; to help others; to do something meaningful; to acquire practical tools; to obtain satisfaction; and to gain experience in the field. It is also important to note that many of the respondents indicated that their expectations had been met. Only a few stated that their expectations were not met, citing reasons such as not enough time to allow them to establish meaningful connections with their recipients, and poor field-staff management. 
The next three research hypotheses $(4,5,6)$ examined the correlations between the various motivations (altruistic / egoistic / materialistic) for carrying out community social activity and long-term effects of such activity. . All three hypotheses were confirmed. It was found that each type of motive examined had a positive long-term influence on the participants in various aspects of their lives (employment, studies, and approach to life). Nonetheless, the regression analysis indicated that the altruistic motive was the strongest predictor of social activity. Furthermore, satisfaction from social activity was the lowest among those who were mostly motivated by altruistic motive. Apparently, it is more difficult to achieve goals deriving from altruistic motivations because its effects are complex, ongoing and therefore more difficult to measure, as opposed to those emerged from egoistic or materialistic motivations. Yet, we found that altruistic motivation is stronger than materialistic motivation in predicting social involvement in the community. This finding is consistent with other studies in the field of motivation (e.g., Deci \& Ryan, 2008; Ryan, 2013).

An unexpected major and interesting finding emerged from our study, namely a significant correlation between respondents' gender and satisfaction derived from community social activity. It was found that $77.8 \%$ of the female respondents reported on high satisfaction from community social activity, compared to $23.8 \%$ of male respondents. This finding, which was not one of the original hypotheses, does not conform to previous studies findings (e.g., Golan \& Goldner, 2016). One possible explanation could be documented differences between the genders with respect to stronger pro-social tendencies among women, such as empathy and helping behavior (e.g. Feshbach \& Feshbach, 1982).

Biological evolutionary theories about the development of empathy offer possible explanations for these differences between women and men, in which inborn differences between the sexes in brain structure and hormone secretion have an impact on the intensified development of emotional abilities in general and of empathy in particular among women (e.g., Zann-Waxler, Shirtcliff, \& Marceau, 2008). These differences are rooted in the traditional evolutionary role of women as caregivers concerned about their offspring. The development of these intensified emotional abilities helps women in this role. Moreove, cultural norms enhance the pattern of gender-compatible differences in expressing emotions. Thus, women are expected to be more helpful, caring and empathic. In line with these expectations, they developed ability to express emotions more than among men (e.g., Martin \& Halverson, 1981). Because empathy is related to helping behavior, the tendency to help others is greater among women than among men. Nevertheless, Eagly (2009) argued that the difference in manifestations of help and altruism among men and women is qualitative rather than quantitative. That is, men's activities to help others usually involve taking heroic measures to help those in distress (for example, saving someone from a life-threatening situation). In contrast, women's activities to help others usually involve providing care and assistance (care giving). This difference in helping tendencies apparently is related to biological-evolutionary variance in traditional gender roles (protection for men and care giving for women). Congruent with these findings, in our study we found that compared to men, a higher percentage of women chose to participate in social community involvement courses, and a higher percentage of women agreed to take part in the study. Moreover, women reported greater satisfaction with their social activity than men.

In conclusion, in accordance with the findings of previous studies, our study reveals a high degree of satisfaction derived from community social activity as part of an academic course, jointly with many advantages accruing to the participating students. These advantages are manifested in the long-term effects in various areas of participants' lives - in career, advanced studies, increasing self-esteem, developing sensitivity and so on. These positive influences reinforce and encourage the Council for Higher Education of Israel to support and finance 
academic courses such as social involvement in the community, for the benefit of the participating students and the society. In addition, in view of the fact that most of the participants reported on being involved in previous community social activity, our findings support the expanding notion that social involvement in educational settings are required from an early age. That is, children should be exposed and involved in such activities at elementary school ages, in order to increase their awareness and their ability to lead social change.

\section{LIMITATIONS AND RECOMMENDATIONS FOR FUTURE RESEARCH}

One of the major limitations of the current study is its small sample size, explained by the relatively small number of students who have participated in the courses of social involvement in the community in Israeli Academic Institutions. Therefore, we recommend of conducting additional similar studies using larger samples, using quantitative and qualitative methods, in order to obtain a more comprehensive and in-depth understanding of the motives and longterm influences of community social activity under the auspices of academic courses. Also, the current study was a retrospective study that examined statistical correlations between variables, which is not allowed for inferences of causality. Therefore, a prospective study comparing research group and control group is required.

\section{References}

Astin, A. W., \& Sax, L. J. (1998). How undergraduates affected by service participation. Journal of College Student Development, 39, 251-263.

Astin, A. W., Sax, L. J., \& Avalos, J. (1999). Long-term effects of volunteerism during the undergraduate years. Review of Higher Education, 22, 187-202.

Brewis, G. (2010). From service to activity? Students, volunteering and community action in mid twentieth century in Britain. British Journal of Educational Studies, 58(4), 439-449.

Brewis, G., \& Holdsworth, C. (2011). University support for student volunteering in England: Historical development and contemporary value. Journal of Academic Ethics, 9, 165 - 176.

Burns, D. (2011). Motivations to volunteer and benefits from Service-Learning: An exploration of marketing students. Journal for Advancement of Marketing Education, 18, 10-23.

Clary, E., Snyder, M., \& Stukas, A. (1998). Volunteers' motivations: Findings from a national survey. Nonprofit Voluntary Sector Quarterly, 25, 485-505.

Cnaan, R.A., \& Goldberg-Glen, R.S. (1991). Measuring motivation to volunteer in human services. Journal of Applied Behavioral Science, 27(3), 269-284.

Council for Higher Education, Planning and Budgeting Committee (2013). Social Involvement-The Third Function of Academia. Booklet published for study day on student and academic involvement in the community [Hebrew].

Deci, E. L., \& Ryan, R. M. (2008). Self-Determination Theory: A Macro theory of Human Motivation, Development, and Health. Canadian Psychology, 49(3), 182-185.

Driham, R. (1999). The factors associated with retention of volunteers. M.A. Thesis, Bar-Ilan University, Ramat Gan [Hebrew].

Eagly, A. H. (2009). The his and hers of prosocial behavior: An examination of the social psychology of gender. American Psychologist, 64(8), 644-58.

Ethridge, E. A. (2006). Teacher modeling of active citizenship via Service-Learning in teacher education. Mentoring and Tutoring, 14(1), 49-65.

Feshbach, N., \& Feshbach, S. (1982). Empathy training and the regulation of aggression: Potentialities and limitations. Academic Psychology Bulletin, 4(3), 399-413.

Golan, D., \& Goldner, L. (2016). Long-term effects of students' participation in civic engagement programs with scholarships. Haifa and Jerusalem: University of Haifa and Hebrew University of Jerusalem [Hebrew].

Hatcher, J.A., \& Studer, M.L. (2015). Service-Learning and philanthropy: Implications for course design. Theory into Practice, 54(1), 11 - 19. 
Hustinx, L., Cnaan, R. A., \& Handy, F. (2010). Navigating theories of volunteering: A hybrid map for a complex phenomenon. Journal for the Theory of Social Behavior, 40, 410-434.

Mobley, C. (2007). Breaking ground: Engaging under graduates in social change through service learning. Teaching Sociology, 35, 125-137.

Mueller, A. (2005). Antidote to learned helplessness: Empowering youth through service. Reclaiming Children and Youth, 14(4), 16-19.

Payton, R. L., \& Moody, M. (2008). Understanding philanthropy: Its meaning and its mission. Bloomington, IN: Indiana University Press.

Prentice, M. (2007). Service-Learning and civic engagement. Academic Questions, 20, 135-145.

Ryan, R. M. (2013). Motivation and the organization of human behavior: Three reasons for the reemergence of the field. In R.M. Ryan (Ed.), The Oxford handbook of human motivation (pp.3-10). New York: Oxford University Press.

Sadan, A. (1997). Empowerment and Community Planning. Tel Aviv: Hakibbutz Hameuchad [Hebrew].

Seider, S. (2007). Catalyzing a commitment to community service in emerging adults. Journal of Adolescent Research, 22, 612-639.

Steinberg, K., Hatcher, J. A., \& Bringle, R. G. (2011). The civic-minded graduate: A north star. Michigan Journal of Community Service Learning, 18, 19-33.

Sullivan, S.C., Ludden, A.B., \& Singleton, R.A. (2013). The impact of institutional mission on student volunteering. Journal of College Student Development, 54(5), 511 - 526. 